BMC JOURNAL OF SCIENTIFIC RESEARCH

A Multidisciplinary Research Journal

ISSN: 2594-3421

\title{
Nutritional Status and Associated Factors among Under Five Children of Slum and Non-Slum Area of Bharatpur Metropolitian City, Chitwan
}

\author{
Govinda Prasad Dhungana ${ }^{1 *}$, Aakriti wagle ${ }^{2}$ \\ dhunganagovindana2012@gmail.com
}

\begin{abstract}
A cross-sectional and comparative study design was used to evaluate the nutritional status and associated factors among under five years' children in Bharatpur Metropolitan City's slum and nonslum area. A total of 246 children under the age of 5 (each of 123 from slum and non-slum) were collected from April 1 to 30; 2017 was interviewed by face to face. Height and weight were measured by anthropocentric measurement and age was reported by direct interview for evaluation of nutrition status.

The prevalence of wasted, stunted and underweight in the slum area was 4.9\%, 28.5\% and 6.5\% respectively, whereas $4.9 \%$ wasted, $21.0 \%$ stunted and $5.7 \%$ underweight in the non-slum area. The study revealed that in slum as well as non-slum areas, the proportion of wasted was the same. Although maximum number of children in the slum had become stunted and underweight as compared to non-slums, but it was no statistically significant.

Factors related to children: sex, early breastfeeding, colostrum feeding, birth weight, breastfeeding exclusiveness and children's number were statistically significant factors for nutritional status in slum while childhood diseases condition was associated factor in non-slum area. Mother related factors: mother occupation, mother height, age of child were associated factors in both settlement. Also, it reveled that that the joint effect was much stronger than the single effect to explorer the predictors of malnuttrition in both settlements.
\end{abstract}

Key words: Nutrition, Slum, Non-slum, under- 5 years' children

\section{Introduction}

Good nutrition in combination with regular physical exercise provides an appropriate, balanced diet but poor nutrition can lead to decreased immunity, enhanced disease susceptibility, impaired physical and mental development, and decreased productivity $[1,2]$. Nutrition is a vital component of health throughout life, particularly vulnerable groups living either slum or nonslum settlements $[3,4]$. Although there have been continuous decreases of under nutrition in recent years, but childhood under nutrition is one of the major dietary issues in the nation and it is equally important in both settlement. In slums, the death rates of under 5 were higher than in non-slum urban areas [4]. Globally, 25 percent of under-five-year children were stunted, 15

\footnotetext{
${ }^{1 *}$ Corresponding Authors- Lecturer- Tribhuvan University, Department of Statistics; Birendra Multiple Campus

${ }^{2}$ Research Officer-School of planning Monitoring Evaluation Research (SPMER)
} 
percent were underweight, and 8 percent were wasted in 2012, particularly high in Asia [5]. In Nepal 36 percent of children in Nepal are stunted among 12 percent are severely stunted, 10 percent of children are wasted among them 2 percent are severely wasted and 27 percent under 5 children are underweight among them 5 percent are severely underweight [6].

Malnutrition is a major public health problem in developing country like Nepal [7]. A recent study from the United Nations Children's Fund (UNICEF) demonstrates that Nepal is one of 10 countries in the global with the greatest prevalence of stunting and one of the top 20 countries with the highest number of stunted children. Malnutrition is a serious obstacle to infant and child survival, growth and development. It also faces serious threats, particularly to the survival of infant and young child, and is connected with one third of childhood mortality [8].

One of the priority programs in our health care system is to address current nutritional issues for children below five years of age [9]. In nutrition programs, the Ministry of Health has adopted new policies including evidence-based interventions and strategies. Initiated in early years with the Growth Monitoring and Breastfeeding Program, the Ministry then introduced a communitybased strategy in subsequent years via the Micro-nutrient Supplementation Program [9].

Malnutrition has the following categories: Growth failure (a) Acute malnutrition (wasted / thinness) (b) chronic malnutrition (stunted/short) and Acute and/or chronic malnutrition (underweight) malnutrition and Micro-nutrient malnutrition [9]. This study can assist to identify the prevalence of growth failure malnutrition and associated factors among under 5 children in slum and non-slum settlement of Bharatpur Metropolitan city.

\section{Methods}

A cross-sectional and comparative study design was conducted in Bharatpur Metropolitan City, Chitwan ward no. 5 and 14. Children aged 6-59 months and their mothers were purposely selected. Sample size was calculated as:

$$
\begin{aligned}
& n=\frac{z_{\alpha / 2}^{2}}{d^{2}} V[10] \\
& \text { Where, } V=p_{1}\left(1-p_{1}\right)+p_{2}\left(1-p_{2}\right)
\end{aligned}
$$

$Z_{\alpha / 2}=$ confidence level and assess the uncertainty of a prevalence estimate from standard normal distribution was 1.645. The difference between two prevalence (permissible error $=\mathrm{d}$ ) has been magnified as 10 percent. Similarly, the prevalence of slum and non-slum settlement of stunted was $(\mathrm{P} 1=38 \%)$ and $(\mathrm{P} 2=36 \%)$ respectively $[6,11]$. A total of 246 children under the age of 5 (each of 123 from slum and non-slum) were collected from April 1 to 30; 2017.

Using face-to-face interview, children under 5 years of age were reported. Height and weight of children under 5 years of age were assessed using non-stretching measuring tape and bathroom scale. Children were allowed to stand bare feet against a wall on a ground for measuring height with feet parallel and joined together with heels and buttock touching the wall. It was made sure 
the head was erect. The height was labeled on the wall with the assistance of a ruler and marker and measured with the measuring tape. Length of child within the 24 months was taken in a supine position. To measure the weight, it was ensured that it was at zero error before weight was measured.

\section{Reliability and Validity}

In order to ensure the reliability and validity of the tools before data collection 10 percent were pre-tested and changed as needed. Before data collection, verbal informed consent was taken from mother of under 5 years' children. Dignity of respondents has been maintained by providing the opportunity to choose to discontinue at any time during the period of data collection.

\section{Measurement and statistical analysis}

The height and weight were transformed according to age and sex to $\mathrm{Z}$ score by reference population value. The explained variable ( $Z$ score) was continuous and either continuous or categorical were covariates. Categorical covariates have been transformed to dummy due to the facts of ANCOVA model regression without interaction [12].

$$
Y_{i}=\beta_{0}+\beta_{1} D_{1 i}+\beta_{2} D_{2 i}+\ldots \ldots+\beta_{k} X_{k}+u_{i}
$$

This model did not explorer the interaction effect between the any two dummy regressors, due to fact the ANCOVA model was done with two level interaction effect [12].

$$
Y_{i}=\beta_{0}+\beta_{1} D_{1 i}+\beta_{2} D_{2 i}+\beta_{3}\left(D_{1 i} \times D_{2 i}\right)+\ldots \ldots . \beta_{k} X_{k}+u_{i} \quad \ldots(2)
$$

The independent variables showed association in bivariate analysis with p-value $<0.10$ and the association might be gross effect and could not tell the real effect of independent variables or may lead to misleading information as a result of confounding effects of other variables in bivariate analysis. Thus, MANCOVA backward regression model was performed for all the variables by controlling confounding and Multicollinearity. Variance Inflation Factor (VIF) $<10$ was used to measure the Multicollinearity as acceptable and p-value $<0.05$ as statistically significant.

MANCOVA without interaction model expressed the relation between the nutritional parameter and different covariates. Value of $\mathrm{R}^{2}$ in slum settlement was $42.1 \%$ by, $56.8 \%$ and $51.1 \%$ in stunted, underweight and wasted while $29.1 \%, 46.1 \%$ and $24.9 \%$ in non-slum respectively. The models showed acceptable homoscedaciticity circumstances standardized residual $[-2,2]$ compared to standardized predicted value.

\section{RESULTS}

\section{Background variables}

A higher percentage of non-slum households (90.0\%) compared to slum households (73.0 $\%)$ had a monthly family income of $\geq$ Rs.10, 000. Nearly one-fourth (23.0\%) and one-tenth $(9.0 \%)$ of mothers gave birth to their child at less than 20 years of age in slum and non-slum respectively. Nearly half $(46.0 \%)$ of mothers had finished only primary education in slum, 
but the largest (78.0\%) mothers had finished secondary / above education in non-slum. House wife as a major occupation of mothers who lived in slum had $87.0 \%$ and non-slum had $80.0 \%$. Slightly greater proportion of mothers' height $(7.0 \%$ vs $5.0 \%)$ had less than $145 \mathrm{~cm}$ in slum and non-slum respectively. The proportion of mothers who had a birth-spacing is less than two years, with the previous child (4.0\% vs $2.0 \%)$ in slum and non-slum area respectively. Likewise, more than third fifth $(63.0 \%$ and $65.0 \%)$ mothers had no feeling of specific problems during pregnancy in both settlements.

\section{Children characteristics}

More than half of under-five children of both slum $(55.0 \%)$ and non-slum $(61.0 \%)$ were male. Slightly greater proportion $(52.0 \%)$ of non-slum mother's breastfeed exclusive to their children up to six months compared to slum areas (50.0\%). In slum $68.0 \%$ of mothers who start breastfeeding in 1 hour is greater than in the non-slum $(50.0 \%)$. The proportion of mothers who did not feed their children with colostrum was more than 3 times $(18.0 \%)$ in a slum compared to a non-slum area $(5.0 \%)$. Likewise, $(9 \%)$ of both slum and non-slum children under five had low birth weights $(\leq 2500$ gram) (table 1$)$.

Table 1: Feeding Practices, ANC, PNC and Birthweight in Slum and Non-Slum

\begin{tabular}{|c|c|c|c|c|}
\hline \multirow{2}{*}{ Variables } & \multicolumn{2}{|c|}{ Slum $(n=123)$} & \multicolumn{2}{|c|}{ Non-slum(n=123) } \\
\hline & Number & Percent & Number & Percent \\
\hline \multicolumn{5}{|c|}{ Exclusive breastfeeding } \\
\hline Up to 6 months & 61 & 49.6 & 64 & 52 \\
\hline \multicolumn{5}{|c|}{ Early initiation of breastfeeding } \\
\hline Yes & 84 & 68.3 & 61 & 49.6 \\
\hline \multicolumn{5}{|l|}{ Colostrum feeding } \\
\hline Yes & 101 & 82.1 & 117 & 95.1 \\
\hline \multicolumn{5}{|l|}{ ANC check-up } \\
\hline$\geq 4$ visits & 87 & 70.7 & 115 & 93.5 \\
\hline \multicolumn{5}{|l|}{ Place of delivery } \\
\hline Health institution & 108 & 87.8 & 118 & 95.9 \\
\hline \multicolumn{5}{|l|}{ Times of PNC } \\
\hline$\geq 3$ visits & 11 & 8.9 & 39 & 31.7 \\
\hline \multicolumn{5}{|l|}{ Type of delivery } \\
\hline Normal & 102 & 82.9 & 81 & 65.9 \\
\hline \multicolumn{5}{|l|}{ Birth-weight } \\
\hline$\geq 2500 \mathrm{gms}$ & 112 & 91.1 & 112 & 91.1 \\
\hline
\end{tabular}

\section{Nutritional Status of under 5 years' children in Slum and Non-Slum}

In both slum and non-slum settlements the prevalence of wasted was equal (4.9\%). Similarly, the slum's stunted prevalence was greater $(28.5 \%)$ than non-slum $(21.1 \%)$. Also, the prevalence of underweight in slums $(6.5 \%)$ was slightly greater than in non-slums $(5.7 \%)$. There were no significant association found between type of settlement and wasted $(p=0.99)$, stunted $(\mathrm{p}=0.184)$ and underweight $(\mathrm{p}=0.79)$ (figure 1$)$. 


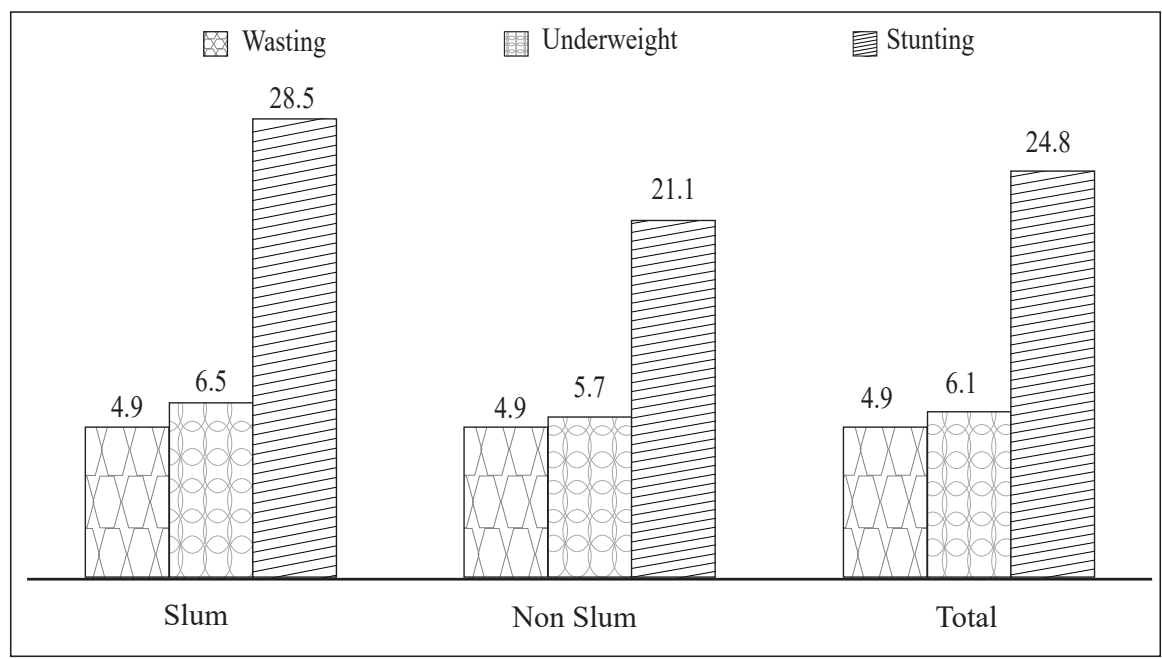

Fig 1: Nutritional status among Under 5 years' children in slum and non-slum

There was positive relation with the nutrition parameter (stunted, wasted and underweight) and birth weight $(\mathrm{p}=0.008$ and.003), height of mother $(\mathrm{p}=0.045)$ and mode of delivery $(p<0.001)$ and adverse relation with number of child $(p=0.013)$, housewife occupation of mother $(p=0.008)$, early initiation of the breasts feeding $(p=0.005 \&<0.001)$, exclusive breastfeeding $(\mathrm{p}=0.019 \& 0.001)$ was observed in slum settlement.

The nutrition parameters and birth weight $(\mathrm{p}=0.018 \& 0.001)$, age of child birth $(\mathrm{p}=0.003$ and $0.002)$ and mother height $(p=0.001)$ were positive relationship, and the adverse relationship between nutritional parameter and presence of illness within one year $(p=0009)$ and not completed immunization ( $\mathrm{p}=0.003$ ) for non-slum areas.

Different predictors include explorers in slums, including number of children, agriculture and housewives as a major occupation of mothers, early breastfeeding, colostrum feeding, mode of delivery and sex. Only few predictors, as an age at child birth, presence of diseases within one year and no complete immunization were predictors were non-slum areas. In slum area, male child had more likely malnourished as compare to female child but it was absence in non-slum area (table 2).

Table 2: Relationship between Nutrition parameter (stunted, wasted and underweight) with Covariates

\begin{tabular}{|c|c|c|c|c|c|c|}
\hline \multirow{2}{*}{ Variables } & \multirow{2}{*}{$\begin{array}{c}\text { Coefficients } \\
\beta\end{array}$} & \multirow{2}{*}{$\mathrm{t}$} & \multicolumn{3}{|c|}{$95.0 \%$ CI for $\beta$} & \multirow[b]{2}{*}{ VIF } \\
\hline & & & p-value & LL & UL & \\
\hline \multicolumn{7}{|l|}{ Slum } \\
\hline \multicolumn{7}{|l|}{ Height for weight (wasted) } \\
\hline Constant & -8.463 & -2.528 & 0.013 & -15.11 & -1.817 & \\
\hline Number of children & -0.289 & -3.18 & 0.002 & -0.469 & -0.109 & 1.233 \\
\hline Birth weight & 0.495 & 2.706 & 0.008 & 0.132 & 0.858 & 1.286 \\
\hline Mothers Occupation (1=agriculture) & -1.971 & -2.563 & 0.012 & -3.498 & -0.444 & 1.239 \\
\hline Early initiation bf $(1=\mathrm{no})$ & -0.509 & -2.384 & 0.019 & -0.934 & -0.085 & 1.117 \\
\hline
\end{tabular}


Colostrum feeding $(1=$ no $)$

Mode of delivery $(1=\mathrm{C} / \mathrm{S}$ or instrumental $)$

\section{Height for age (stunted)}

Constant

Height of the mother

Birth weight

Mothers occupation (1=housewife)

Sex of child ( $1=$ male)

Exclusive breastfeeding $(1=$ no)

Weight for age (underweight)

Constant

Sex of child (1=male)

Exclusive breastfeeding $(1=$ no)

Early initiation of breastfeeding $(1=$ no $)$

Colostrum feeding $(1=$ no $)$

Mode of delivery $(1=\mathrm{C} / \mathrm{S}$ or instrumental $)$

\begin{tabular}{cccccc}
-0.967 & -3.644 & $<0.001$ & -1.494 & -0.44 & 1.272 \\
0.977 & 3.649 & $<0.001$ & 0.445 & 1.509 & 1.148 \\
& & & & & \\
-8.469 & -2.684 & 0.009 & -14.731 & -2.206 & \\
0.042 & 2.028 & 0.045 & 0.001 & 0.083 & 1.244 \\
0.565 & 3.047 & 0.003 & 0.197 & 0.933 & 1.300 \\
-0.968 & -2.687 & 0.008 & -1.682 & -0.253 & 1.659 \\
-0.564 & -2.770 & 0.007 & -0.968 & -0.160 & 1.190 \\
-0.452 & -2.193 & 0.031 & -0.860 & -0.043 & 1.230 \\
& & & & & \\
-8.253 & -3.399 & 0.001 & -13.073 & -3.433 & \\
-0.445 & -2.634 & 0.010 & -0.780 & -0.110 & 1.301 \\
-0.485 & -3.015 & 0.003 & -0.804 & -0.166 & 1.196 \\
-0.571 & -3.338 & 0.001 & -0.910 & -0.231 & 1.150 \\
-0.612 & -2.883 & 0.005 & -1.033 & -0.191 & 1.279 \\
1.220 & 4.536 & $<0.001$ & 0.686 & 1.754 & 1.899 \\
\hline
\end{tabular}

Non-slum

\section{Height for weight (wasted)}

(Constant)

Birth weight

$\begin{array}{lllll}-0.433 & -0.464 & 0.644 & -2.287 & 1.421\end{array}$

$\begin{array}{lllll}0.450 & 2.412 & 0.018 & 0.080 & 0.820\end{array}$

1.177

Height for age (stunted)

Constant

Age at child birth

Height of the mother

Disease within year (1=yes)

Weight for age (underweight)

Constant

Age at child birth

Height of the mother

Birth weight

Disease within year $(1=$ yes $)$

$\begin{array}{ll}-16.058 & -4.729\end{array}$

0.000

$\begin{array}{ll}-22.79 & -9.325\end{array}$

0.079

3.094

0.003

0.028

0.129

0.070

3.308

0.001

0.028

0.112

1.074

$-0.590$

$-2.681$

0.009

$-1.026$

$-0.154 \quad 1.042$

$\begin{array}{lllll}-12.075 & -3.876 & 0.000 & -18.26 & -5.887\end{array}$

$\begin{array}{lllll}0.175 & 3.220 & 0.002 & 0.067 & 0.284\end{array}$

$\begin{array}{lllll}0.066 & 3.377 & 0.001 & 0.027 & 0.106\end{array}$

7.758

0.559

$3.400 \quad 0.001$

0.2320 .886

1.294

$\begin{array}{llllll}-0.501 & -2.680 & 0.009 & -0.872 & -0.129 & 1.193\end{array}$

$\begin{array}{llllll}-1.051 & -3.033 & 0.003 & -1.740 & -0.363 & 1.275\end{array}$

$\begin{array}{lllll}-1.051 & -3.033 & 0.003 & -1.740 & -0.363\end{array}$

$L L=$ Lower limit, $U L=$ Upper limit, $C I=$ confidence interval, VIF = Variance Inflation Factor

This model did not explorer the interaction effect between the any two dummy regressors, due to fact the MANCOVA model was done with two level interaction effects.

The nutrition parameters (stunted, wasted and underweight) with birth weight $(p<0.001)$ and mother's height $(p<0.001)$ were positive relation, and adverse relationship between nutritional parameter with numbers of children $(\mathrm{p}=0.001)$ in slum. Likewise, positive relationship between nutritional parameter and birth weight $(p=0.002 \& 0.001)$, child age of birth $(p=0.021)$ and mother height $(p=0.001)$ in non-slum, whereas negative relationship between nutritional parameters and all two level interaction effects in both settlement.

The coefficient of regression of all two levels of interaction was higher as compared to single variables in both settlement, it was statistically significant. This showed that the joint effect was much stronger than the single effect (table 3). 
Table 3: Relationship between Nutrition parameter (stunted, wasted and underweight) with/without interaction effect of covariates

\begin{tabular}{|c|c|c|c|c|c|c|}
\hline \multirow{2}{*}{ Variables } & \multirow{2}{*}{$\begin{array}{c}\text { Coefficients } \\
\beta\end{array}$} & \multirow{2}{*}{$\mathrm{t}$} & \multirow{2}{*}{ p-value } & \multicolumn{3}{|c|}{$95.0 \% \mathrm{CI}$ for $\beta$} \\
\hline & & & & LL & UL & VIF \\
\hline \multicolumn{7}{|l|}{ Slum } \\
\hline \multicolumn{7}{|l|}{ Weight for height (wasted) } \\
\hline (Constant) & -1.534 & -2.357 & 0.020 & -2.823 & -0.244 & \\
\hline Total number of children & -0.335 & -3.382 & 0.001 & -0.532 & -0.139 & 1.109 \\
\hline Birth weight & 0.865 & 4.244 & $<0.001$ & 0.461 & 1.268 & 1.067 \\
\hline Mother occupation $\times$ Colostrum feeding & -2.825 & -3.123 & 0.002 & -4.616 & -1.033 & 1.026 \\
\hline Mode of delivery $\times$ Complete immunization & -1.923 & -1.727 & 0.087 & -4.128 & 0.283 & 1.554 \\
\hline \multicolumn{7}{|l|}{ Height for age (stunted) } \\
\hline (Constant) & -12.508 & -4.887 & $<0.001$ & -17.58 & -7.436 & \\
\hline Birth weight & 0.615 & 3.794 & $<0.001$ & 0.294 & 0.936 & 1.217 \\
\hline Height of the mother & 0.063 & 3.589 & $<0.001$ & 0.028 & 0.097 & 1.098 \\
\hline Mother occupations $\times$ Sex of child & -0.594 & -3.273 & 0.001 & -0.954 & -0.234 & 1.115 \\
\hline \multicolumn{7}{|l|}{ Weight for age (underweight) } \\
\hline (Constant) & -2.257 & -5.027 & & -3.147 & -1.367 & \\
\hline Birth we & 0.653 & 4.764 & $<0.001$ & 0.381 & 0.925 & 1.127 \\
\hline Sex of child $\times$ Exclusive breast feeding & -0.845 & -4.226 & $<0.001$ & -1.241 & -0.449 & 1.211 \\
\hline Exclusive $b$ & -1.012 & -3.429 & 0.001 & -1.597 & -0.427 & 1.502 \\
\hline Early & -0.785 & -3.249 & & -1.263 & -0.306 & 1.717 \\
\hline Early initiation & -1.080 & -1.916 & 0.058 & -2.197 & 0.038 & 1.828 \\
\hline \multicolumn{7}{|l|}{ Non-slum } \\
\hline \multicolumn{7}{|l|}{ Height for age (stunted) } \\
\hline (Constant) & -15.396 & -4.514 & $<0.001$ & -22.15 & -8.638 & \\
\hline Birth weight & 0.533 & 3.209 & 0.002 & 0.204 & 0.862 & 1.115 \\
\hline Mother height & 0.074 & 3.415 & 0.001 & 0.031 & 0.117 & 1.033 \\
\hline Exclusive breast feeding $\times$ Early initiation & -0.572 & -1.809 & 0.073 & -1.199 & 0.054 & 1.972 \\
\hline \multicolumn{7}{|l|}{ Weight for age (underweight) } \\
\hline (Constant) & -1.958 & -3.257 & 0.002 & -3.150 & -0.765 & \\
\hline Birth $v$ & 0.598 & 4.651 & $<0.001$ & 0.343 & 0.853 & 1.262 \\
\hline Age at child birth & 0.109 & 2.344 & 0.021 & 0.017 & 0.201 & 9.136 \\
\hline Sex of child $\times$ Colostrum feeding & -1.641 & -2.891 & 0.005 & -2.767 & -0.515 & 1.878 \\
\hline Exclusive breastfeeding $\times$ Complete immunization & -3.343 & -8.245 & $<0.001$ & -4.147 & -2.539 & 2.154 \\
\hline Early initiation $\times$ Colostrum feeding & -0.914 & -1.954 & 0.053 & -1.842 & 0.014 & 1.684 \\
\hline
\end{tabular}

$L L=$ Lower limit, $U L=$ Upper limit, $C I=$ confidence interval, VIF= Variance Inflation Factor

\section{Discussion}

The finding of the present study revealed that the prevalence of stunting in slums $(28.5 \%)$ was higher than in non-slums (21.1\%) but prevalence of wasted and underweight was $4.9 \%$ and $6.5 \%$ in the slum, where there was no significant difference between $4.9 \%$ and $5.7 \%$ in the non-slum area respectively. The findings of this study are somehow similar to the study of under-nutrition in slum areas in Nigeria city where stunted was common in the slum (16.8\%) as in non-slum areas (6.9\%) [13]. Likewise, findings of the research in Pune's urban slums (2012) are quite different in which the prevalence of underweight was $34.3 \%$, stunted $58.7 \%$ and wasted was $16.9 \%$ [14]. A study of Meshram et.al (2018) in India with a prevalence of wasted, stunted 
and underweight in urban slum area was found to be $4.2 \%, 22.9 \%$ and $17.17 \%$ respectively [15]. Different research findings were variation due to variability in sample size, study area, and measurement methodology about stunting, wasting and underweight. Despite this same methodology, the finding is different, it may be the financial status of the study population and their individual physical growth development and it is also variation in benchmarks of slum and non-slum area in different countries.

The findings of this research showed that the prevalence of malnutrition is small compared to NDHS 2016, where the prevalence of wasted, stunted and underweight is $10 \%, 36 \%$ and $27 \%$ respectively [5]. The lower prevalence of malnutrition may be limited to one metropolitan city due to smaller sample size and limited study area. Likewise, Bharatpur is a major city with varying sources of income. That's why parents handle enough food for their child as needed, but the same situation does not apply throughout the nation.

Male child prevalence had a greater risk of malnutrition compared to female child in both slum and non-slum areas. The finding of this research was considerably more stunted boys (35.8\%) compared to girls (19.6\%) in the slum but contrast to Pune (2012) finding the prevalence of underweight and stunted had more in girls [14]. The comparable finding with this research was Kathmandu Valley, which showed that male children in slums were more stunted than female children [11]. The finding is variation because the perception of our community has a high level of male child care than female child, but in our country, under-five mortality is higher in boys than in girls [6].

This research showed that low birth weight was the major determinant of malnutrition as it was substantially associated with all three parameter of nutritional status (stunted, wasted and underweight). Birth weight was also statistically important in the impact of two-level interaction, as it was a major determinant of malnutrition. Exclusive breastfeeding, early initiation of breast feeding, colostrum feeding, and immunization are also determinants of malnutrition. The research in the urban slum of Nagpur (2013) and another study from Bangladesh (2007) revealed that the main associated variables of malnutrition were low birth weight, absence of exclusive breastfeeding and incomplete immunization similar to this research, but in comparison to the research of Nagpur, the literacy and socio-economic status of women were associated factors with malnutrition. This predictors are contrast with the present study [16, 17].

This research also showed that stunting was substantially connected with mother's height $(\mathrm{p}=$ 0.027) and birth-weight $(\mathrm{p}=0.001)$ which is similar to the Bangladesh study of acute malnutrition determinants in which mother's height and birth-size were significantly associated with factors[16 ].

The study in the Kapilbastu district showed that the gap between two pregnancies over two years, recommended exclusive breast-feeding, complete immunization had a positive effect on the health of children which is similar to the findings of this study but socio-economic status, in contrast to the study in the Kapilbastu district, the age of the mother is not associated with nutritional status in this study [18]. 


\section{Conclusion}

The prevalence of wasted, stunted and under-weight is $4.9 \%, 28.5 \%$ and $6.5 \%$ in the slum area, respectively whereas, $4.9 \%$ wasted, $21.1 \%$ stunted and $5.7 \%$ underweight in non-slum area. The research showed that in both slum and non-slum areas, the number of wasted children are equivalent and stunted number of children are higher in slum as compare to non-slum but there was no significant relationship between the settlement type and any nutritional indicators.

More predictors are identified in slum area as compare to non-slum area. Children related factors: child sex, early breast-feeding, colostrum feeding, birth-weight, exclusive breastfeeding and number of children were statistically significant with nutritional status in the slum, whereas presence of any childhood disease within one year, birth-weight and complete immunization of the child were significantly associated with nutritional status in the non-slum. Mother associated factors: mother occupation, mother height, child birth age were statistically significant factors with nutritional status in both settlement.

The regression coefficient of all two levels of interaction is higher as compared to individual measurement of variables, it is statistically crucial. This showed that the joint effect is much stronger than the single effect.

\section{Limitation of the study}

- The study area covers only two wards of Bharatpur metropolitan city and small sample size it may not reflect the real image of nutritional status all over the metropolitan city.

- Edema was the significant confounder variable for identifying the nutritional status but researcher have not concentrated on edema in this study.

- Researcher used only WHO criteria to evaluate the nutritional status and they do not focused on other methods

\section{References}

[1] WHO Health Topics: Nutrition available at http://www.who.int/topics/nutrition/en/ accessed on 15 March; 2017

[2] Dhungana GP: Nutritional status and associated factors of under 5 years children of Nepal: Multidisciplinary peer-reviewed journal; year 34 11(2018); pp-136

[3] WHO Ten facts on Nutrition: Updated an August 2017 available at http://www.who.int/features/ factfiles/nutrition/en/ accessed on 25 Nov.; 2017

[4] UN-HABITAT, The state of world cities, 2006/7

[5] Joint UNICEF - WHO - The World Bank Child Malnutrition Database: Estimates for 2012

[6] Ministry of Health, Nepal; New ERA; and ICF. 2017. Nepal Demographic and Health Survey 2016. Kathmandu, Nepal: Ministry of Health, Nepal

[7] Dhungana,G.P. Nutritional Status and the Associated Factors in Under Five Years Children of Lamjung, Gorkha and Tanahun Districts of Nepal. Nepalese Journal of Statistics, 1(2017), pp 15-18.

[8] Nutrition strategy, UNICEF; https://www.google.com.np/search?q=Nutrition+strategy $\% 2 \mathrm{C}+\mathrm{UNICEF} \& \mathrm{rlz}=1 \mathrm{C} 1 \mathrm{CHZL}$ enNP806NP806\&oq=Nutrition + strategy $\% 2 \mathrm{C}+$ UNICEF\&aqs $=$ chrome.69i57j012.4557j0j8\&sourceid $=$ chrome \&ie $=$ UTF- 8 
[9] Department of Health services (DoHS), Annual Report 2016/17

[10] World Health Organization. Epidemiological and Statistical Methodology Unit. (1986). Sample size determination: a user's manual. Geneva: World Health Organization. Available on http://www. who.int/iris/handle/10665/61764

[11] Helen Keller International, Nepal; Available on https://www.hki.org/helen-keller-international-nepal

[12] Gujarati, Damodar N. Basic of Econometrics, 4th ed., McGraw-Hill, New York, 2004

[13] Ndukwu CI, Egbuonu I, Ulasi TO, Ebenebe JC. Determinants of undernutrition among primary school children residing in slum areas of a Nigerian city. Nigerian journal of clinical practice. 16(2013):178-83.

[14] Mamulwar M, Rathod H, Jethani S, Dhone A, Bakshi T, Lanjewar B, Jadhav S, Bhawalkar J. Nutritional status of under-five children in urban slums of Pune. International Journal of Medicine and Public Health. 4(2014):247.

[15] Meshram, Tarachand Tukaram, and Ashish Wasudeo Khobragade. "Socio-demographic determinants of malnutrition among school going children in an urban slum area of central India with special reference to nutritional anaemia." International Journal of Community Medicine and Public Health 5.9 (2018): 4009-4011.

[16] Rahman A, Chowdhury S. Determinants of chronic malnutrition among preschool children in Bangladesh. Journal of biosocial science. 2(2007):161.

[17] Dhatrak P, Pitale S, Kasturwar N, Nayse J, Relwani N. Prevalence and epidemiological determinants of malnutrition among under-fives in an urban Slum, Nagpur. National J Community Med. 1(2013): 91.

[18] Bhandari TR, Chhetri M. Nutritional status of under five-year children and factors associated in Kapilvastu District, Nepal. J Nutr Health Food Sci. 1(2013):1-6. 